\title{
Injerencias en los procesos espaciales en ciudades brasileñas dinamizadas por el agronegocio: el caso de Primavera do Leste
}

\author{
Lívia Maschio Fioravanti \\ Universidade de São Paulo(USP), São Paulo, Brasil \\ Instituto Federal de Mato Grosso (IFMT), Mato Grosso, Brasil. \\ Email: liviageousp@gmail.com
}

Resumen: Tomando lo urbano como eje de investigación, dilucidamos la producción del espacio de las ciudades cuyos estudios generalmente enfatizan los flujos de aquello que se dice agronegocio, considerándolas como apoyo para la infraestructura y los servicios requeridos por el sector agrario. Partiendo de los procesos que atraviesan la ciudad de Primavera do Leste, ubicada en el centro-oeste de Brasil, defendemos que la concentración de tierra, de poder y de capital es la base de una urbanización brasileña controlada por un pequeño grupo de poseedores del poder económico y político. La injerencia ejercida por los "pioneros” de estas ciudades (que se consideran hoy parte del agronegocio) establecidas en medio a la dicha expansión de la frontera agrícola de la década de 1970, va más allá de la propiedad privada, alcanza las variadas dimensiones de la vida cotidiana y es uno de los elementos que explican la creciente segregación espacial.

Palabras clave: Urbano; agronegocio; frontera; concentración de tierra; Primavera do Leste.

\section{Interferences in spatial processes in brazilian cities driven by agribusiness: the case of Primavera do Leste}

\begin{abstract}
Assuming the urban as the guiding perspective of our investigation, we shed light on the production of space in cities whose studies generally emphasize the movements of so-called agribusiness, considered a support for the services and infrastructure required for agriculture. Based on the processes that permeate the city of Primavera do Leste, in the midwest of Brazil, we defend the hypothesis that the concentration of land, power and capital is at the foundation of an urbanization controlled by a small group of people who hold the economic and political power. The interference exercised by the "pioneers" of these cities, characterized today by their agribusiness and established within the so-called expansion of the agricultural frontier starting in the 1970s, goes beyond private property. It reaches a variety of aspects in everyday life and is one of the elements that explains the intensified spatial segregation.
\end{abstract}

Keywords:Urban; agribusiness; frontier; land concentration; Primavera do Leste.

\section{Ingerências sobre os processos espaciaisnas cidades brasileiras dinamizadas pelo agronegócio: o caso de Primavera do Leste}

Resumo: Tendo no urbano o eixo norteador de nossa investigação, elucidamos a produção do espaço de cidades cujos estudos geralmente enfatizam os fluxos do chamado agronegócio, considerando-as como suporte aos serviços e infraestruturas exigidos pelo agrário. Partindo dos processos que perpassam a cidade de Primavera do Leste, no centrooeste do Brasil, defendemos que a concentração de terra, de poder e de capital está nos alicerces de uma urbanização brasileira controlada por um pequeno grupo de detentores do poder econômico. A ingerência exercida pelos "pioneiros" dessas cidades hoje consideradas do "agronegócio”, implantadas no bojo da chamada expansão da fronteira agrícola a partir da década de 1970, vai além da propriedade privada. Alcança as mais variadas dimensões da vida cotidiana e é um dos elementos que explica o acirramento da segregação espacial. 
Palavras-chave: Urbano; agronegócio; fronteira; concentração fundiária; Primavera do Leste.

\section{Introducción}

La ciudad Primavera do Leste, ubicada en el sureste de la provincia de Mato Grosso, Brasil (Figura 1), fue concebida y asentada en las décadas de1970 y 1980, en el marco del proceso de expansión de la acumulación territorial del capital del centro-sur hacia las regiones centro-oeste y norte de Brasil. La mayoría de las investigaciones sobre estas ciudades cuya urbanización está ligada más estrechamente al "agronegocio"1 como el caso de Primavera do Leste- se hace desde el punto de vista agrario. Este enfoque caracteriza a las ciudades, en gran medida, como apoyo de servicios e infraestructura requeridas por las actividades agrícolas.

Figura 1.

\section{Ubicación de Primavera do Leste en el centro-oeste brasileño y en la provincia de Mato Grosso.}
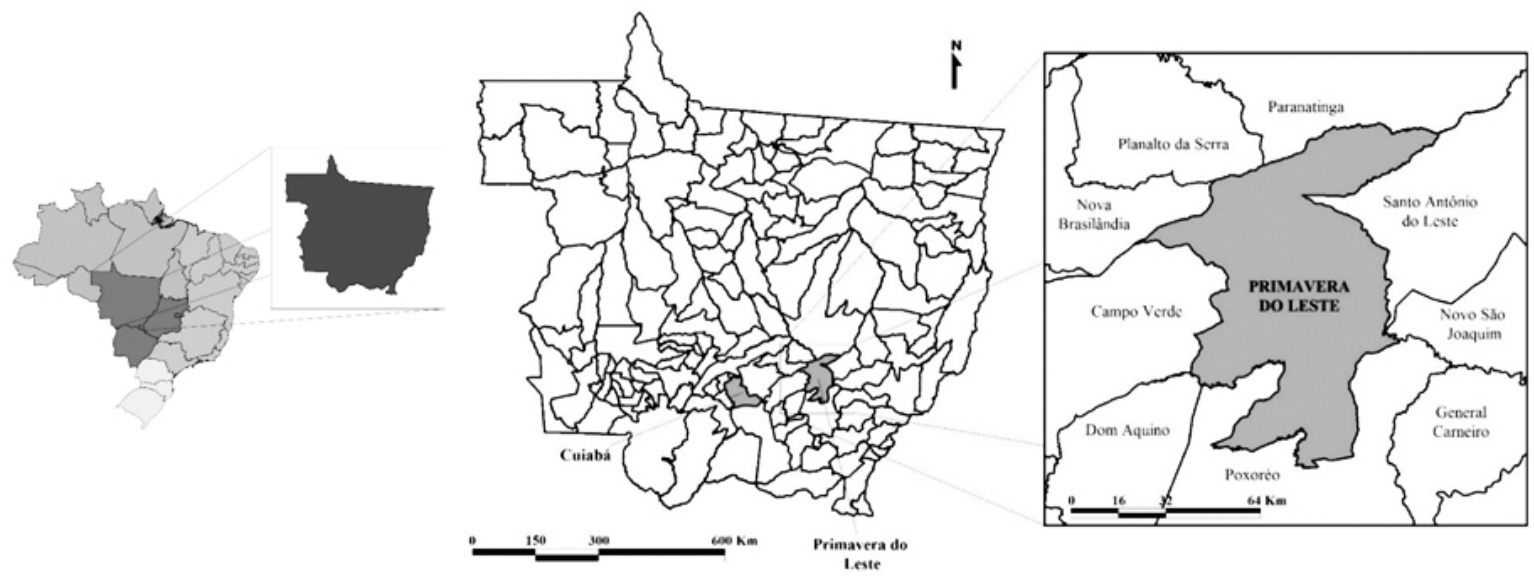

En el mapa a la izquierda, se destaca la provincia de Mato Grosso, en la región centro-oeste de Brasil. En el mapa del centro, Primavera do Leste aparece en relación a los otros municipios de la provincia, con énfasis en la capital, Cuiabá. Por último, el mapa a la derecha muestra los municipios que bordean la ciudad. Fuente: Alcântara, W. y Fioravanti, L., 2018.

Nuestra investigación busca revertir la mirada generalmente utilizada en los estudios de las ciudades que emergen como principales productoras del "agronegocio" — y especialmente de soja — en Brasil. Avanzamos en el debate académico acerca de estas ciudades, (re)ubicando el dominio de lo urbano en los procesos de producción del espacio -no en el ámbito agrario o técnico. Relativizamos, por lo tanto, la importancia de la agricultura capitalista en el proceso de ocupación y producción de estas ciudades, admitiendo que el negocio con la propiedad privada de la tierra fue igual o más importante que aquel que se hizo con la soja.

El objetivo de este artículo es, desde lo urbano y desde una perspectiva crítica sobre la producción del espacio, dilucidar los fundamentos de las contradicciones espaciales de Primavera do Leste. Para eso, tenemos que considerar que Primavera do Leste nace urbana, desde el inicio de su elaboración y planificación a finales de los 1970, y ya como un gran negocio.

El modo por el cual la propiedad fue dominada y fraccionada por los grandes empresarios del centro-sur de Brasil se ha traducido en una creciente concentración de tierras, capital y poder. El fuerte nudo que se ha hecho entre estos tres elementos -detallados en los trabajos del sociólogo brasileño Martins (1994; 2000), y que se presenta como una de las características fundacionales de la sociedad brasileña- nos ayuda a explicar las 
contradicciones espaciales de Primavera do Leste ya iluminar los actuales conflictos en el uso del espacio, particularmente los que toman en cuenta el espacio de reproducción del capital y los de la reproducción de la vida misma.

Con un enfoque metodológico marxista-lefebvriano, mediante una investigación cualitativa basada en instrumentos como la búsqueda bibliográfica y la investigación documental, además de la realización de trabajos de campo y entrevistas semiestructuradas, se profundizará en este artículo el debate sobre las prácticas de injerencia de los “pioneros” todavía ejercidas sobre los procesos de urbanización. Respondemos, de esta manera, a la pregunta sobre cual el alcance del control de los "pioneros" en los procesos espaciales de una ciudad brasileña dinamizada por el "agronegocio", en un proceso que tiene la propiedad privada como fundamento, pero que va mucho más allá, abarcando las múltiples y concretas relaciones de la vida cotidiana.

\section{Por una investigación desde lo urbano}

Tener lo urbano como el punto de partida y a la producción del espacio como hilo conductor de nuestras investigaciones trae, necesariamente, un nuevo abordaje a la manera por la cual las ciudades han sido producidas en el contexto de la expansión de la frontera del capital. Partimos de la premisa de que el capital, dirigido hacia lo que en la década de 1980 se constituía como frontera en el sureste de Mato Grosso, es esencialmente urbano-industrial. En ese momento, los capitales excedentes del centro-sur brasileño necesitaban expandirse territorialmente, en una búsqueda por nuevas posibilidades de la acumulación.

La frontera del capital que se producía en la realidad brasileña a fines del siglo XX era esencialmente urbana, y tenía en la urbanización la condición, el producto y el contenido de su expansión (Santos, 2015). Esta frontera sumamente urbana no sólo precedió a la consolidación de las propiedades destinadas, aunque parcialmente, a las actividades agrarias -considerar el término "frontera agrícola"-, como también se convirtió, como veremos a continuación, en un gran negocio. La mayor parte de las ciudades que nacieron en este contexto, como Primavera do Leste, fueron asentadas desde una lógica racional y emprendedora. Las tierras rodeadas y dominadas en este momento eran las tierras "de negocio", y no las “de trabajo" o de la "supervivencia"2. Desde el principio, fueron insertadas radicalmente en el mundo de la mercancía, con un propósito bien específico: posibilitar el aumento de la acumulación de capital. Así, el objetivo de la expansión de la frontera del capital para el centro-oeste y Amazonia nunca fue, de hecho, la expansión de la producción agropecuaria (Becker, 1982; Martins, 1997; Oliveira, 1997; Moreno, 2007).

Las tierras dominadas en la expansión de la frontera eran, sobre todo, tierras para reserva patrimonial y reserva de valor (Oliveira, 1997, 2007), usadas por los capitalistas principalmente para la especulación y la obtención de incentivos fiscales -que eran abundantes en el régimen militar brasileño y repartidos en los programas de incentivos a la ocupación de la Amazonia Legal ${ }^{3}$. En ese momento, más allá de la tierra como alternativa para la inversión, los incentivos fiscales y financieros eran lo que atraía a las grandes compañías para la frontera (Becker, 1982).

Considerar la frontera que se producía en ese momento como agrícola o de la técnica contribuye, incluso, para ocultar el "carácter rentista" del capitalismo brasileño ${ }^{4}$. Esencialmente, no había interés en la producción agrícola, sino en la "producción de fincas" (Martins, 1997), que, divididas en lotes, configuraban una estrategia y una rentable "producción de ciudades”. Por lo tanto, la mercancía que atraía a los inversores más importantes en el momento de la expansión de las fronteras de la región centro-oeste, y específicamente en el caso del sureste de Mato Grosso, era la propia tierra, y la posibilidad de implementación de la renta capitalista de tierras. Es fundamental analizar los proyectos agropecuarios establecidos en la frontera del centro-oeste y norte de Brasil teniendo en cuenta el hecho de que la combinación de los incentivos fiscales, los terrenos baratos y subsidiados, y el excedente de mano de obra disponible para las empresas que desarrollaban estos proyectos, transformó la urbanización desplazada en el territorio en el negocio mismo (Santos, 2015).

Dominar de manera privada extensas porciones de tierra -generalmente a un precio irrisorio y adquirida por medio de incentivos fiscales o de otro mecanismo de estafa y ocupación ilegal (Moreno, 2007)-y fragmentarlas 
y lotearlas, asentando ciudades, fue, de por sí y por lo menos en los primeros años de ocupación de la frontera, una actividad quizás tan rentable como el propio cultivo, tratamiento y comercialización de soja -cuya producción depende de grandes inversiones de capital para la adquisición de insumos y maquinaria.

Los fundamentos y las contradicciones del espacio de producción de estas ciudades, conocidas por el dinamismo de lo agrario, pueden, en este sentido, ser mejor iluminados desde lo urbano. El aumento del precio medio de la hectárea ocurrido en los primeros años de la ocupación de Primavera do Leste llegó a los dos mil por ciento (Oliveira, 1997), dato que nos da la dimensión de que la "invención” y la“producción” de ciudades eran extremadamente rentables a los negocios de la frontera. La producción de estas ciudades y los grandes proyectos de colonización en Mato Grosso permitieron la realización de la renta capitalista de tierras. La colonización era, de esa manera, un "gran negocio económico" (Moreno, 2007, p. 179) y "locus de la producción del capital” (Oliveira, 1997, p. 331).

Según la perspectiva crítica que adoptamos sobre la producción del espacio, no conviene nombrar las ciudades hoy vinculadas más intensamente a la agricultura capitalista mecanizada como "ciudades del campo" o "ciudades del agronegocio" ${ }^{5}$, puesto que pasan a definirse por un rasgo económico hegemónico externo a ellas. "En las zonas donde las tierras se usan para la producción de commodities internacionales a ser exportadas -principalmente carne y grano-, la extensión de las grandes propiedades de monocultivo no puede prescindir de la centralización urbana”(Volochko, 2013, p. 24). Esta centralización urbana cubre, según Volochko (2013), una centralización técnica (por medio de actividades de control y gestión de la producción), política (a través de políticas dirigidas al "agronegocio”) y económica (puesto que están en la ciudad las infraestructuras y servicios). Es necesario destacar que no estamos negando el rasgo agrario de las ciudades, sino relativizándolo a través de un cambio analítico y desviándonos de un abordaje que mira, desde una perspectiva económica, a las ciudades cuya provincia es la más grande productora de soja de Brasil.

Es necesario, pues, repensar la manera como se examina la relación entre el campo y la ciudad, o más bien, entre lo agrario y lo urbano. Hay más que una interdependencia -camino de investigación que, incluso, puede incurrir en dicotomías. La centralidad de la investigación no está, por lo tanto, en las siembras de soja y su cadena de producción -ella misma a menudo contemplada de manera fragmentada, entre lo que ocurre antes, adentro y después de la tranquera-, sino en lo urbano y en los elementos que nos permiten aprehender la producción del espacio de Primavera do Leste.

Para analizar de manera más detallada la imbricación de lo agrario y lo urbano, se toma en cuenta lo que defiende Lefebvre (2006). Según el autor, habría una tendencia a la urbanización completa de la sociedad según un proceso nombrado por el concepto de sociedad urbana. Esta sociedad nacería, pues, de la industrialización en un proceso que "domina y absorbe la producción agrícola" (Ibid, p. 15). Lefebvre sostiene que la sociedad urbana se presentaría como una sociedad virtual en un proceso cuya constitución tiene continuidades y discontinuidades. Es una sociedad "hoy virtual, mañana real" (Lefebvre, 2004, p. 15) y que cambia, en su formación, las relaciones del campo a través de la expansión del tejido urbano. Todavía según el enfoque de Lefebvre (2004, p. 17), este tejido urbano, definido como el "conjunto de las manifestaciones de la predominancia de la ciudad sobre el campo", "prolifera, se extiende, erosiona los residuos de la vida agraria". Aunque con remanentes de la racionalidad industrial, y realizándose de manera desigual en el tiempo y en el espacio, la expansión de una forma de vida sumamente urbana es proceso clave para comprender la urbanización completa de la sociedad.

Prenunciada y nombrada por Lefebvre, hace casi cinco décadas, la urbanización completa de la sociedad hoy en día está puesta -aunque críticamente. Habría una “urbanización planetaria” (Brenner, 2014), lo que nos lleva a reflexionar sobre los procesos constituyentes de la producción del espacio urbano, abandonando necesariamente las dicotomías entre campo y ciudad, rural y urbano. Frente a una sociedad urbana y nuevos procesos redimensionados de lo urbano, estamos de acuerdo con Brenner sobre la necesidad de una teoría de lo urbano que no esté hecha desde "afuera”, desde un "no-urbano".

La separación entre lo "urbano" y lo "no-urbano" crearía, en este sentido, obstáculos a la comprensión de los procesos de urbanización y de las contradicciones de estas ciudades, en parte vinculadas al "agronegocio". 
Además, si por un lado se nota la descentralización de parte del sector productivo de muchas empresas vinculadas al "agronegocio" del centro-sur de Brasil con la instalación de nuevos ramos o sucursales en Mato Grosso y otras provincias (Volochko, 2013), por otro, no hay una línea que separe lo que sería un "capital de lo agrario" y lo que sería un "capital de lo urbano". El capital, principalmente a partir de los años 2000, pasa a responder a mecanismos que son propios del mercado financiero. Se invierte y reinvierte dónde y cómo sea más conveniente, de modo que hablar en una especificidad de un capital sumamente urbano o agrario oscurecería nuestra investigación. Así, ante una nueva realidad concreta de la imbricación de lo agrario/urbano, campo/ciudad, es oportuno debatir y caminar hacia una nueva teoría que también rompa con dicotomías y considere la extensión del tejido urbano, en un movimiento que revele como el campo mismo es eminentemente urbano.

\section{La producción de la frontera económica y la urbanización como negocio}

Primavera do Leste es el resultado de un proyecto previamente elaborado y calculado, que comenzó a finales de 1970 con la expansión de la frontera del capital. En este momento, los capitales centrados en el sureste y sur de Brasil se dirigían hacia el centro-oeste y norte del país, en una expansión de la frontera económica en favor de los grandes grupos empresariales. La expansión de la frontera ocurría por medio de la concentración de tierras y de los más diversos arcaísmos, como el carácter rentista del capitalismo brasileño y la necesidad de mecanismos vinculados específicamente a la producción de capital, basados los dos en prácticas como la servidumbre por deuda y la ocupación ilegal de tierras (Martins, 1994).

A partir de la década de 1970 y por medio de diferentes políticas territoriales de ocupación, el régimen militar brasileño comienza a patrocinar de manera más intensa el acceso de los grandes grupos económicos, nacionales e internacionales, a la tierra en la Amazonia Legal. Al invertir en la frontera, estos grupos tenían como objetivo primero la exención fiscal, y no el desarrollo de la agricultura o ganadería (Oliveira, 1997). En consecuencia, diferentes proyectos de colonización, públicos y privados, fueron intencionalmente malogrados -comparado a lo previsto oficialmente- y muchos de ellos, incluso ante el discurso del Estado de ocupar la Amazonia Legal, basaban sus acciones en una de las actividades económicas que menos necesitan de mano de obra, la ganadería (Becker, 1982; Martins, 1997; Oliveira, 1997).

Becker (1982) destaca que el monopolio de la tierra en las regiones de frontera tenía una especificidad que reducía su carácter de frontera agrícola, una vez que la producción agropecuaria era limitada. Frente a esta producción irrisoria de lo que podría efectivamente haber sido implementado por los empresarios que se hacían propietarios y tenían amplio apoyo estatal, Santos (2015) cuestiona el término "agrícola" usado con respecto a la frontera en este momento:

... aunque considerando sus limitaciones, la observación del desarrollo de la ganadería como actividad económica en estas condiciones, solamente fortalece la relatividad, y quizá mismo, la inadecuación del adjetivo "agrícola” cuando empleado en relación a la situación de frontera. La ganadería surgió también como actividad primordial en el proceso de avance dinámico de la frontera, fundamentalmente, porque, por sus bajos coeficientes de capitalización inicial, se consolidó como instrumento de apropiación de largas extensiones de tierra, que servían, simultáneamente, como estrategia de defensa contra la inflación, como fuente de renta asociada a la valoración de las tierras, y como medio para la obtención de incentivos fiscales de cualquier tipo(p. 123).

Relativizando los contenidos de la dicha frontera agrícola, Becker (1982) enfatiza que lo que interesaba a las grandes compañías atraídas a las regiones de la frontera en centro-oeste y norte de Brasil no era la producción para el mercado interior y ni tampoco la ganadería o la agricultura. Los intereses estaban dirigidos, efectivamente, a la "apropiación de la tierra, o a disfrutar de los incentivos y financiamientos, para diversificar inversiones, crear reservas de valor y abrir nuevos espacios para la penetración del capital” (Ibid, p. 176). En este contexto, la mayoría de las empresas que dirigían parte de su capital a la frontera tenían su sede en São Paulo, además de capitales urbano-industriales y proyectos desarrollados en la Superintendência para o Desenvolvimento da Amazônia (SUDAM) ${ }^{6}$. 
El establecimiento de Primavera do Leste fue resultado precisamente de estos incentivos fiscales del Gobierno para la ocupación de la Amazonia Legal. En 1971, un economista de São Paulo, considerado por los habitantes de Primavera do Leste como uno de los principales "pioneros" de la ciudad, creó la compañía Primavera do Oeste, en asociación con empresarios del sector automotriz y de la industria azucarera y alcoholera. El objetivo declarado era desarrollar un proyecto agropecuario fomentado por la SUDAM, sin embargo, como profundizaremos a continuación, los negocios con la tierra se convirtieron en una actividad altamente rentable.

Como se puede notar, fue por medio de los "pioneros" que llegaron a la región de Primavera do Leste grandes empresarios, subvencionados por el Estado- que se amplió la frontera del capital. Se estrechaba la relación entre tierra, poder y capital (Martins, 1994; 2010). Las dinámicas de la propiedad privada de la tierra son fuertemente determinadas por las aproximaciones entre el poder económico y el político. En este contexto, el proceso de ocupación de tierras en Mato Grosso tuvo la particularidad de privilegiar la monopolización de la propiedad privada de la tierra, presentando un complejo aparato jurídico y político que abrió espacio a mecanismos de estafa y corrupción, y tuvo como consecuencia la prelación de intereses de los sectores hegemónicos económicos y políticos (Moreno, 2007).

Así, como ocurrió tendencialmente en el territorio de Mato Grosso -y en todo Brasil-, el dominio privado de tierras y la ocupación de lo que vendría a ser la ciudad Primavera do Leste conservaron y fortalecieron los privilegios económicos y políticos de oligarquías, permitiendo, siempre con la contribución y el fuerte patrocinio del Estado, que los grandes empresarios fuesen también propietarios y participasen del juego político.

El proyecto Ciudad Primavera fue implementado en 1972 a partir de la desmembración de una sola finca, de uno solo dueño, y emprendido con los recursos de la Colonizadora Cosentino, responsable, hasta la emancipación política de la ciudad en 1986, por una serie de inversiones y obras de infraestructura. Primavera do Leste fue idealizada como gran negocio -y como negocio eminentemente urbano. Si por una parte era necesario realizar el proyecto Ciudad Primavera para garantizar la reproducción de los capitales urbano-industriales del centro-sur de Brasil, incluso por medio de los proyectos agrarios previstos para la región, por otra, los negocios de la urbanización se transformarían en algo tan relevante como las propias actividades direccionadas a la comercialización de granos. La dominación privada de grandes propiedades por grupos de empresas establecidos en el momento de la ocupación de la frontera de Mato Grosso- y la manipulación de la renta de la tierra son la base de las contradicciones del espacio de Primavera do Leste.

Todavía hoy, la colonizadora responsable por el loteo de lo que vendría a ser, formalmente, la ciudad de Primavera do Leste tiene en sus manos parte significativa de los inmuebles terrenos en alquiler o venta, controlando la expansión o implementación de loteos -junto con otras pocas constructoras y promotoras inmobiliarias cuyos dueños también son de familias esencialmente "pioneras” en el proceso de ocupación y producción de la frontera.

\section{Ciudad cautiva: la ciudad que tiene dueño}

Será a través de la comprensión de que la dominación de extensas propiedades se ha hecho por medio de una estrecha relación entre tierra, poder y capital que profundizaremos algunos de los aspectos relacionados a la urbanización oligopolista. Volochko (2015) emplea este término con respecto a las ciudades más fuertemente vinculadas al "agronegocio", y se refiere a una urbanización controlada, hasta hoy, por familias y grupos que llegaron al inicio de la expansión de la frontera. En la urbanización oligopolista, ocurre un mayor control sobre la propiedad privada, generando un mayor dominio sobre la apertura de loteos, el tamaño de las cuotas y el costo de los lotes e inmuebles. En la Figura $2^{8}$, vemos claramente que las mismas familias dominan gran parte de las tierras ocupadas y los loteos abiertos en los núcleos urbanos ya consolidados de Primavera do Leste. 
Figura 2.

Urbanización oligopolista en Primavera do Leste, Mato Grosso.

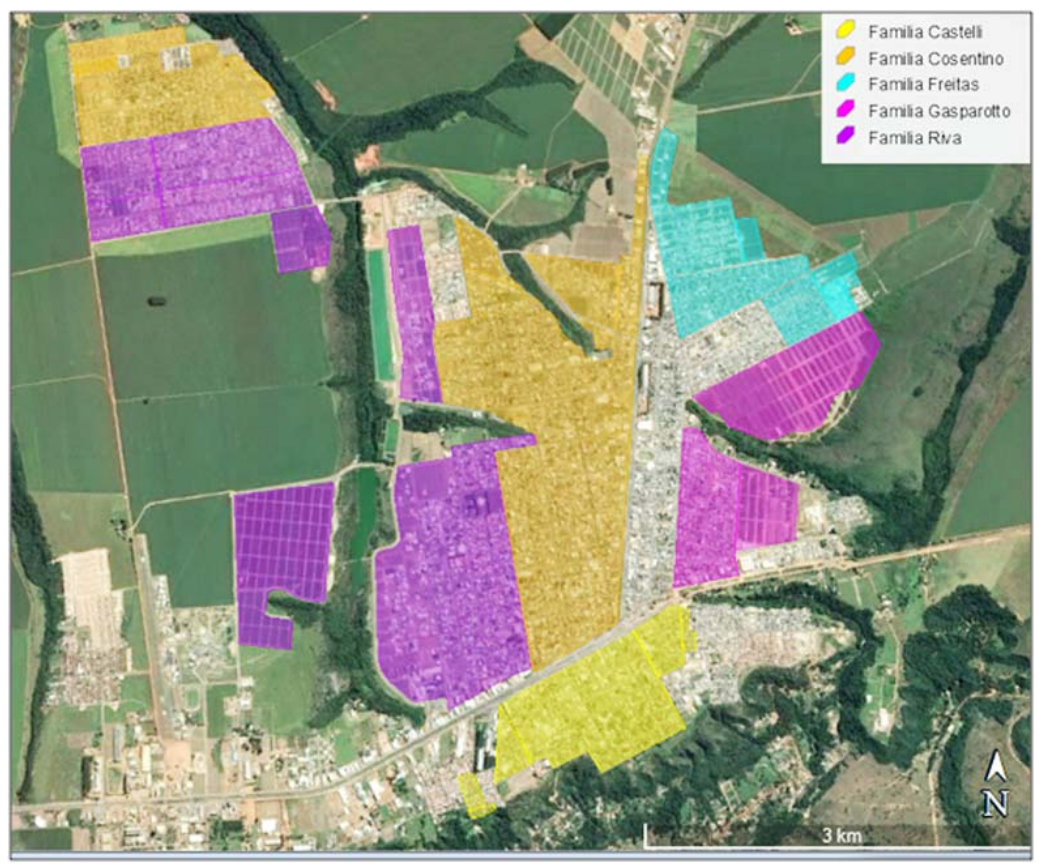

Fuente: Elaborado por el autor

Se nota, a partir de la imagen, una fuerte injerencia en la expansión de los loteos y en el planeamiento urbano, llevada a cabo por pocas familias desde el inicio de la ocupación de la ciudad. Los "pioneros" utilizan tácticas diversas para manipular la renta capitalista de tierras y para controlar la valoración del suelo urbano, como la donación de tierras, apertura gradual de nuevos loteos y venta de lotes por precios más baratos de los que suele haber en la ciudad -al principio de la ocupación para estimular la llegada de nuevos habitantes y actualmente en un proceso destinado a la construcción de proyectos que valoran el loteo mismo.

La dominación y concentración de tierras en Primavera do Leste ocurrieron mientras las fincas se loteaban para la creación y expansión del área construida de la ciudad. Así, los propios dueños de los latifundios -con finalidad improductiva o destinados a las actividades agrarias- son también dueños de los terrenos en el núcleo urbano o en las áreas a su alrededor. En este marco, el establecimiento de la "tierra cautiva" en el curso de la ocupación de Primavera do Leste trajo la producción de lo que nombramos ciudad cautiva.

Llena de arcaísmos de las prácticas agrarias brasileñas -entre ellas, la concentración de tierras y la preponderancia de tierras improductivas con finalidad rentista- la ciudad cautiva tiene como consecuencia una lógica excluyente: ni todos pueden tener acceso a la propiedad, lo que, en una sociedad capitalista, tiende a determinar el propio acceso a la ciudad. De la misma manera, la propiedad y la ciudad comienzan a convertirse, como tendencia, en privilegio solamente de las clases de renta de mayor poder adquisitivo. La ciudad cautiva es una ciudad que tiene dueño. En el caso de Primavera do Leste y su proceso de urbanización oligopolista, unos pocos dueños: hombres, blancos y procedentes del centro-sur de Brasil.

La noción de ciudad cautiva también permite discutir la superposición entre los sectores público y privado, una fuerte característica de la sociedad brasileña (Martins, 1994). La ciudad, producida socialmente -en una sociedad capitalista, dominada de manera privada- y que es pública, tiene su aspecto privado subrayado. El trinomio tierra-poder-capital nos explica también el hecho de que muchos "pioneros” de las ciudades más estrechamente vinculadas al "agronegocio" sean hoy alcaldes u ocupen otros puestos públicos, 
En este sentido, la ciudad cautiva, generada a partir de la concentración en pocas manos de tierras, poder y capital, reproduce los diferentes mecanismos de dominación de cada uno de estos elementos de manera articulada, asegurando que sigan siempre los mismos grupos en el control. La imbricación de las élites económicas con la política queda evidente cuando observamos quienes ocupan los puestos de gestión municipal de estas ciudades dinamizadas, en parte, por el "agronegocio" -cuyos intereses están también estrechamente asegurados en el marco provincial y nacional. En Primavera do Leste, los últimos dos alcaldes -cada uno con por lo menos tres mandatos- siguen la tendencia: uno es hacendado y otro, dueño de una compañía del sector agrícola.

En Lucas do Rio Verde, Otaviano Pivetta -accionista mayoritario de una de las más grandes empresas agrícolas del país, Vanguarda Agro - fue considerado el alcalde más rico del país en 2012, según su declaración de bienes ante la Justicia Electoral brasileña. Su hermano, Adriano Pivetta, fue también alcalde de la ciudad vecina, Nova Mutum, donde está ubicada parte de las tierras, justo, de Vanguarda Agro. Otro caso representativo es el de Blairo Maggi -uno de los dueños del Grupo Amaggi, empresa brasileña con fuerte actuación en el agronegocio y, especialmente, en la comercialización de la soja-, que fue gobernador provincial de Mato Grosso por dos mandatos, senador por la provincia de Mato Grosso y, de mayo de 2016 a enero de 2019, Ministro de la Agricultura, Ganadería y Abastecimiento.

Todos estos casos implican personas o familias que llegaron mientras se constituía la frontera de Mato Grosso, a partir de la década de 1970, y que hoy en día tienen significativo poder político. En estas ciudades, marcadamente dinamizadas por el "agronegocio", los "pioneros" están presentes no como abstracciones o personajes de un pasado lejano: ellos son hoy agentes hegemónicos de los procesos de urbanización y producen y reproducen estrategias económicas con repercusiones en la vida práctica.

Ellos tienen, por lo tanto, un papel crucial en el mando de las estrategias espaciales -de valorización del espacio urbano-, actuales y futuras. Aparecen en columnas sociales locales, son galardonados como ciudadanos de Mato Grosso o de Primavera, participan de eventos locales -como ferias del "agronegocio" y fiestas- y frecuentan los mismos espacios de socialización que muchos otros habitantes -como asados o pescarías promovidas por grandes compañías, o eventos en el Centro de Tradições Gaúchas (CTG). La gente mira a estos "pioneros" como modelos a seguir, estándares de éxito cuya determinación y esfuerzos parecen poder ser replicados a toda la población -o, por lo menos, a la que, en el discurso y de acuerdo con el sesgo ideológico que exalta el "pionerismo" y la meritocracia, no tiene miedo de trabajar, tiene determinación, sabe emprender y esperar el merecido rendimiento del trabajo arduo.

El dominio de los dueños sobre la ciudad va más allá del control de la propiedad, tiene que ver con otras dimensiones. Está en la determinación y elección del trazado de la ciudad, con la imposición de un espacio abstracto y funcional, contribuyendo a la programación, en el tiempo y en el espacio, de las actividades de la vida urbana. También cubre aspectos vinculados a la vida cotidiana y que fueron dibujados a lo largo del proceso de ocupación de Primavera do Leste por los propios dueños y por otras familias "pioneras". La ciudad cautiva es, en este sentido, lo que se valora con respecto a la cultura y a la perspectiva sobre la vida y el trabajo -conectados a la idea de que, en estas ciudades, y para todos, se puede enriquecer solo por el esfuerzo y trabajo. También se manifiesta en el prejuicio -algunas veces oculto, otras explícitamente-con relación a los indígenas o a la gente del noreste del país, y en el habla de los residentes.

De acuerdo con lo dicho, en la ciudad cautiva -cuyos procesos constituyentes no están solo en Primavera do Leste, sino posiblemente en otras ciudades establecidas por pocos y con el propósito específico de manejo de la renta de la tierra, mediada o no por lo agrario- el peso de la homogeneidad surge en un nivel más alto. La homogeneidad se impuso desde el inicio de los procesos de producción de la frontera: con incentivos y oportunidades ofrecidos a los empresarios del centro-sur, que se convirtieron en propietarios y pasaron a controlar gran parte de las tierras, en una dinámica que hoy trae profundas y dramáticas consecuencias para aquellos que no tienen acceso a la propiedad.

Así, en la ciudad cautiva, la homogeneidad está no solamente en los aspectos relacionados con la propiedad y la tierra-mercancía, sino en un control exagerado de otros procesos que se refieren a la urbanización de 
Primavera do Leste. Se manifiesta desde la monotonía del trazado urbano y del patrón arquitectónico, elegidos de manera general por los "pioneros" y siguiendo las líneas adoptadas por algunos pocos arquitectos famosos de la ciudad, hasta las decisiones que derivan de las más diferentes instituciones, cuyos representantes hacen parte de las oligarquías económicas y políticas o han sido específicamente designados por los "pioneros".

Es importante remarcar que los procesos que nos permiten describir Primavera do Leste como "ciudad cautiva” son producidos y reproducidos en otras ciudades, en un movimiento en el que el control de clase sobre la propiedad privada es uno de los fundamentos de la urbanización brasileña en general. Según Burgarelli et al.(2016), respecto a la concentración de tierra en la metrópoli São Paulo:

El uno por ciento de los dueños de inmuebles de São Paulo concentra el 45\% del valor inmobiliario de la ciudad. Son R 749 mil millones en casas, departamentos, terrenos y otros bienes de raíces registrados bajo el nombre de 22.4 mil propietarios. (p. 1, traducción nuestra)

Si en la metrópoli de São Paulo este control exacerbado sobre la tierra está en manos de 22 mil propietarios, en la producción del espacio de Primavera, además del hecho de la ciudad tener muchísimos menos inmuebles y habitantes que São Paulo, los dueños de la ciudad se pueden contar con los dedos de una mano -lo que crea un monopolio aún más grande en la dinámica de tenencia de tierras, y se aprietan las amarras de la “cautividad” respecto la propiedad y la ciudad. La injerencia en estas ciudades dinamizadas por el "agronegocio" ocurre en una dimensión superior: son pocos los dueños al mando de una cantidad de tierra mucho más grande, en términos proporcionales al núcleo urbano construido o programado para expansión. De este modo, si por una parte los loteos enteramente controlados por estos pocos "pioneros" enriquecidos pueden ser fácilmente comparados, en términos territoriales, con barrios de las metrópolis brasileñas, por otra, representan con frecuencia a la mayor parte del área construida en estas ciudades cuya urbanización está más estrechamente asociada al "agronegocio".

Además de la compra y venta de fragmentos del espacio urbano, homogeneizado y mercantilizado, hay una hegemonía en los procesos de producción del espacio urbano vinculados a los grandes y rentables negocios urbanos. A diferencia de las metrópolis, donde hay una relativa diversificación de los agentes responsables por el desarrollo inmobiliario, en una ciudad cautiva como Primavera do Leste, los agentes están por lo general reunidos en una sola persona, familia o grupo empresarial: el propietario del terreno, el loteador, el corredor de bienes de raíces, y, teniendo en cuenta la superposición de las oligarquías económicas y políticas, en cierta medida, por el Estado mismo ${ }^{10}$. En este marco, el poder de unos pocos en decidir sobre el ritmo de la dinámica inmobiliaria -desde la incorporación de lotes a los límites de la ciudad, incluyendo la obtención de renta y la valoración del espacio- se lleva a cabo, por lo tanto, en procesos de magnitud e intensidad más grandes.

Es importante subrayar que el establecimiento de Primavera do Leste y de otras ciudades como "cautivas”, además de haber sido posible solamente por la conservación de los privilegios económicos y políticos que históricamente favorecieron a las oligarquías en Brasil, también está relacionado a las prácticas vinculadas a los mecanismos mismos de producción de capital, como la ocupación ilegal de tierras y la servidumbre por deuda. En Primavera do Leste, por ejemplo, según el sitio de georreferenciación del Instituto Nacional de Colonização e Reforma Agrária (INCRA), algunos de los terrenos del núcleo urbano son todavía tierras públicas -aunque se utilizan y comercializan de manera privada. Aparte de eso, con respecto a las prácticas de intercambio de favores y preferencias personales en detrimento de lo público (Martins, 1994), hay al menos tres situaciones investigadas por el Ministerio Público que implican pago de coima por propietarios a concejales, con la intención de acelerar o aprobar el establecimiento de loteos.

Se encuentran situaciones similares en las ciudades Lucas do Rio Verde y Sorriso. En Lucas, el propio alcalde parece ser responsable por la apertura de loteos. La empresa Novo Tempo Imobiliário Ltda., de la cual era dueño hasta el inicio de su mandato en 2017, fue creada a partir de un proyecto de loteo de un área de $1,000,000 \mathrm{~m}^{2}$. Este lugar, que pasó a inscribirse en el perímetro urbano, era hasta entonces una finca del alcalde. Según datos del sitio de la inmobiliaria Novo Tempo, 544 lotes tienen propósito comercial y residencial, todos con más de $800 \mathrm{~m}^{2}$ y dirigidos a la gente de alto poder adquisitivo. Esta inmobiliaria hizo el primer loteo cerrado de la ciudad, con lotes a partir de $899 \mathrm{~m}^{2}$ y área total de $203.7 \mathrm{mil} \mathrm{m}^{2}$. El alcalde, además de haber sido acusado 
de utilizar el puesto municipal en provecho propio, también solicitó a la Secretaria de Estado de Infraestrutura e Logística la pavimentación y drenaje en una avenida ubicada exactamente entre sus dos nuevos loteos (Gosch, 2017).

En Sorriso, municipio responsable por la mayor parte de la producción de granos del país, la familia considerada "pionera" es actualmente una de las más ricas de la provincia de Mato Grosso. La familia llegó a la región en la década de 1970 y fundó la Colonizadora Feliz, hoy dirige el Grupo Francio -cuyas áreas de actuación incluyen el sector inmobiliario, la comercialización de lotes rurales y urbanos, la ganadería porcina, la extracción y comercialización de madera y también actividades agrícolas. La antigua colonizadora y actual Inmobiliaria Feliz estuvo a cargo del asentamiento y loteo de todo el núcleo urbano inicial de la ciudad. En treinta años, fueron más de seis loteos, con otros cuatro en 2016 y 2017. Uno de ellos tenía la intención (en julio de 2017),según el material promocional de la inmobiliaria, de ser el más lujoso loteo de Mato Grosso, con 319 lotes, de $525 \mathrm{~m}^{2}$ y costo a partir de 600 mil reales.

De la misma forma que en Primavera do Leste y Lucas do Rio Verde, se nota en Sorriso la construcción de una ciudad cautiva engendrada a través de la conservación y reproducción de contenido arcaico de producción del capital, así como de las relaciones espaciales colmadas del "poder del retraso"11 que tanto caracteriza a la sociedad brasileña.

Miembros de la familia "pionera” de Sorriso fueron acusados, en 2007, de ser responsables de una extracción ilegal de madera en el Parque Indígena do Xingu. También fueron procesados por el Ministério do Trabalho por haber mantenido a sus trabajadores en situaciones análogas a la servidumbre en haciendas del municipio de Vera y de Feliz Natal (Siqueira, 2007; Fanzeres, 2007). Según el reportaje publicado en el periódico Folha de São Paulo, de 20 de marzo de 2007, otra integrante de la familia fue acusada de haber comprado votos en las elecciones municipales de 2004, después de haber ofrecido beneficios personales y la liquidación de las cuotas del inmueble para favorecer a uno de los candidatos al puesto de alcalde de la ciudad.

Finalmente, la Colonizadora Feliz - que sigue haciendo loteos de la finca adquirida por la familia en la constitución de la frontera- tenía negocios, por lo menos hasta 2013, que "parecían envueltos en irregularidades como mediciones equivocadas u otras irregularidades en la emisión de la escritura" (Almeida, 2013, p. 31, traducción nuestra). La colonizadora habría adquirido tierras que estaban en disputa. Uno de sus "pioneros" llegó incluso a admitir la existencia de más de 200 invasores en la tierra que daría lugar a la ciudad (Ibid).

Estas ciudades que surgen en la narrativa nacional como resultante de una heroica historia de "pionerismo" y trabajo arduo se producen a partir de mecanismos de acumulación de capital vinculados a prácticas de acumulación primitivas -ocupación ilegal de la tierra, extracción de madera, relaciones de trabajo análogas a la servidumbre-, así como de prácticas cruzadas por intercambios de favores -como compra de votos en período electoral y corrupción para la aprobación de loteos.

Lo más perverso de la ciudad cautiva se manifiesta en la población expropiada de las condiciones mínimas de supervivencia, y que vive en las periferias o en viviendas precarizadas. La parte más pobre de la población no es considerada bienvenida por los dueños de la ciudad o por aquellos que pasaron a tener la "legitimidad” para vivir y pertenecer a la ciudad por inscribirse en patrones sociales específicos -sobre todo, por ser ricos y blancos.

Según Cerutti (2004), las antiguas colonizadoras hoy actúan bajo la forma de promotoras inmobiliarias, constructoras o inmobiliarias, y ejercen un fuerte control sobre "la propiedad y la población, distribuyendo en el espacio los migrantes o expulsando aquellos que los responsables de las empresas de comercialización de la tierra consideran indeseables” (Ibid, p 23, trad. nuestra). Enfatizando las prácticas variadas de monitoreo y control de los más pobres de Primavera do Leste, el autor denuncia haber existido una selección hecha a fines de 1990 -en las palabras del alcalde de la ciudad-, para decidir, entre aquellos con menor renta, quienes podrían vivir en cada barrio. En lugares más distantes del centro de la ciudad, loteos enteros fueron cedidos o vendidos a precios más bajos para la población de menor renta. 
El control sobre la población es aún más claro cuando se miran a las personas sin hogar. Generalmente, realizando actividades temporarias y precarias en las haciendas ligadas al "agronegocio”, ellos representan cuerpos cuya permanencia en la ciudad y su visibilidad son frecuentemente negadas por aquellos que tienen legitimidad para habitarla.

Se hizo una amplia campaña en los medios locales entre los años 1999 y 2000 para construir la imagen de que las personas sin hogar - peyorativamente llamadas de pés-inchados (pies-hinchados)- eran naturalmente perezosas o violentas. Residentes de la ciudad relataron, incluso, numerosos casos en que se concedieron pasajes a sus ciudades de origen, además del uso de mecanismos de expulsión forzosa, como autobuses o camiones pasando al amanecer a "recoger” los pobres y “llevarlos” a las ciudades vecinas. Además de los medios locales, se usaban también mecanismos como las detenciones por vagancia hasta el año 2000, una práctica ampliamente utilizada en la dictadura militar brasileña para las detenciones sin base jurídica. Por último, y teniendo como objetivo contribuir para una ciudad que desea "firmarse a través de una imagen de limpieza, organización y prosperidad de todos los que componen su espacio” (Cerutti, 2004, p. 31), el refugio municipal -concluido al final de la década de 1990 y administrado por la Iglesia Católica- tuvo un rol importante ejerciendo presión para que las personas sin hogar trabajasen o regresasen a sus ciudades, con el compromiso de no volver en un plazo de seis meses ${ }^{12}$.

Estas prácticas de dominio del espacio buscan asegurar los intereses de la clase de los “pioneros” de la ciudad, junto a los empresarios, el poder público, la policía y la iglesia católica. Como vimos, son muchas las tácticas usadas para mantener intacta la imagen de “ciudad vidriera” del "agronegocio” y donde se supone que prospera la calidad de vida, en un movimiento de injerencia que no sólo implica la propiedad -aunque esté en ella fundamentado-, sino también las prácticas de control sobre quienes pueden permanecer en la ciudad divididos entre los que pueden elegir donde vivir y los que tienen que pasar por una selección para que se defina el barrio donde se permite su morada- y aquellos que, en última instancia, deben ser expulsados.

La pobreza permitida es la que puede permanecer escondida en lugares remotos y controlados. En las ciudades más fuertemente articuladas por el "agronegocio”, "hay una producción controlada y planeada de guetos pobres, generalmente, al borde de la carretera o en los extremos de la ciudad, ligados a una población tolerada mientras sea proveedora de servicios básicos” (Volochko, 2013, p. 33). Las periferias de estas ciudades cuentan con un control y un planeamiento más incisivo de parte del Estado, albergando una "pobreza tolerada” solamente como mano de obra barata, en local y hora determinados -con el uso del espacio y del tiempo controlado y vigilado. Los grandes conjuntos residenciales destinados a la población de menor renta se ubican en estas ciudades, por lo general, al otro lado de las carreteras -en relación al centro-, o detrás de silos o almacenes y, por lo tanto, lejos de la mirada de los otros habitantes.

En Primavera do Leste, existen 1.200 casas del Programa Minha Casa Minha Vida (PMCMV) ${ }^{13}$, ubicadas en dos grandes conjuntos residenciales en las periferias de la ciudad: el conjunto Padre Onesto Costa, en el loteo Primavera III, y el Residencial Gutiérrez, en el loteo Tuiuiú, respectivamente, a 8km y 6km del centro, donde no son bien atendidos por infraestructura y servicios urbanos. En Sorriso, se entregó en julio de 2017, a través del mismo programa del gobierno federal, el conjunto residencial Mario Raiter, con 1.271 casas de $46 \mathrm{~m}^{2}$, cuya predicción es albergar 5.088 mil personas (Ribeiro, 2017). Este conjunto residencial se encuentra en el sureste de la ciudad, en un lugar relativamente lejos del centro -avanzando por la carretera MT242-, después de la concentración de las infraestructuras para uso industrial y almacenamiento y tratamiento del grano.

En Lucas do Rio Verde, el más grande conjunto residencial de la ciudad es conocido como Tessele Júnior y tiene cerca de 1.500 casas para los trabajadores del conglomerado BRFoods. Albergando una población estigmatizada por los otros residentes, se encuentra en el extremo noroeste de la ciudad. Como enfatiza Volochko (2013, pp. 27-28), ese es un “proceso claro de segregación socio-espacial de una población empobrecida y migrante, que satisface las necesidades y estrategias de producción de una empresa que tiene un poder enorme en la producción del espacio urbano, cada vez más controlado y segregado/segregador”. 


\section{Consideraciones Finales}

La captura de tierras en la producción de la frontera de Mato Grosso a partir de la década de 1970, tuvo su fundamento en la dominación capitalista de grandes extensiones de tierra para la reserva patrimonial y de valor e hizo posible el control del mercado de la tierra y, por decirlo así, de los procesos de urbanización en pocas manos. En una perspectiva todavía poco estudiada con respecto a las ciudades dinamizadas por el "agronegocio", buscamos elementos que destacasen el establecimiento de la ciudad de Primavera do Leste como un gran negocio. En consecuencia, se consideró que los negocios con la tierra eran tan relevantes en la producción de la frontera cuanto aquellos con la producción, almacenamiento, tratamiento y comercialización de granos.

La dominación capitalista de la propiedad privada, que se inició con el avance de la frontera del capital y la ocupación de Primavera do Leste, trajo profundas consecuencias a la urbanización y a las relaciones concretas de la vida cotidiana. Los dichos "pioneros" movilizaron no sólo un poderoso monopolio sobre la propiedad capitalista de la tierra para la realización de sus estrategias espaciales, sino también llevaron a cabo prácticas y mecanismos de control sobre los diversos aspectos de la vida urbana. En este sentido, la ciudad cautiva está no sólo bajo el dominio -con respecto al espacio y al tiempo- de la dinámica agraria: abarca las relaciones sociales concretas, en un proceso en el cual la injerencia de ese grupo selecto enriquecido en las relaciones espaciales, nos lleva, aunque con discontinuidades, a recordar aquello que los coroneles solían hacer en sus viveros de votos en el siglo XX. Así, exactamente en un marco de creciente mundialización y financiación, es necesario considerar el significativo lugar de las oligarquías y de las élites locales, constituidas históricamente, en estas ciudades -muchas veces, incluso, de manera asociada a los grandes conglomerados internacionales.

El control de la tierra, del capital y del poder -regido por pocas manos en el rápido proceso de creación de la frontera de Mato Grosso, cuyos nudos se actualizan todos los días por medio de prácticas nuevas e imbuidas del tan persistente "poder del retraso"-tiene como una de sus consecuencias la dificultad aún más grande de que las personas con renta más baja tengan acceso a vivienda y propiedad; y se constituye como uno de los elementos que nos ayudan a comprender la creciente segregación espacial en las ciudades cautivas del "agronegocio". Si la desigualdad y la segregación son inherentes a la producción del espacio capitalista, permitiendo reflexionar acerca de lo que tiene en común con las ciudades más diversas, este mayor control de la propiedad nos permite abrir caminos para entender lo que estas ciudades tienen de específico con relación a los aspectos más generales de la urbanización brasileña.

\section{Agradecimientos}

Fuente de financiamiento y agradecimiento: La traducción de este artículo se financio con recursos PROEX/CAPES del Programa de Posgrado en Geografía Humana de La Universidad de São Paulo/ Traductora: Nina Jacomini Costa (jacomini.nina@gmail.com).

\section{Notas}

\footnotetext{
${ }^{1}$ Comprendemos "agronegocio" como aquello que Oliveira (2007) nombra "agricultura capitalista", es decir, la agricultura que produce bienes (principalmente, commodities) para ser vendidos mayormente en el mercado mundial y que tiene como objetivo fundamental la acumulación. Usamos este término entre comillas conscientes de que se utiliza con un fuerte sesgo ideológico, exaltándolo como una actividad que podría traer el crecimiento económico y desarrollo social, y que -en el discurso difundido por los medios de comunicación y empresarios- está prácticamente exenta de daños sociales y ambientales.

${ }^{2}$ Empleando terminologías de Martins (1997).

${ }^{3}$ Forma parte de la Amazonia Legal brasileña las provincias de Acre, Amapá, Amazônia, Mato Grosso, Pará, Rondônia, Roraima y Tocantins, y parte de Maranhão.

${ }^{4}$ Sobre el carácter rentista del capitalismo brasileño, véase Martins (2010).

${ }^{5}$ Según Elias (2006), las “ciudades del agronegocio" son las diseñadas y producidas principalmente para atender a los intereses y a las demandas de este sector. La expresión fue inspirada en el término empleado por Santos (2008) "ciudad del campo” y designa las
} 
ciudades en que hay una hegemonía de las funciones de atención a las demandas del “agronegocio” con relación a las otras actividades de la ciudad.

${ }^{6}$ Según Becker (1982), la SUDAM (Superintendência de Desenvolvimento da Amazônia) es un instrumento de política económica y territorial del Gobierno, que tiene el objetivo de desarrollar programas para involucrar la Amazonia en los procesos de reproducción de capital de manera aún más intensa.

${ }^{7}$ La idea misma de "pionerismo” debe ser relativizada, porque está cargada de un sesgo ideológico que se refiere a la gente que había llegado en aquel momento como los primeros a ubicarse en el lugar. Considera, de esa manera, la región como un "vacío demográfico" y no toma en cuenta, entre otras, las poblaciones indígenas. Por otra parte, son considerados “pioneros”aquellos que llegaron en el curso de la expansión de la frontera del capital y que, en un discurso local cargado de meritocracia, supieron invertir, enriqueciendo y alcanzando rendimiento, valorado como resultado de su esfuerzo en el trabajo. Es tomando todos estos aspectos en consideración que utilizamos, en este artículo, los términos “pionero” y “pionerismo” entre comillas.

${ }^{8}$ Este mapa es una aproximación a la realidad, propuesta para que se pueda comprender la urbanización oligopolista de Primavera do Leste, y presenta generalizaciones, una vez que muchos de los lotes ya han sido vendidos a terceros y que una representación exacta puede hacerse únicamente con el dato de registro de cada inmueble de la ciudad. Como procedimientos metodológicos para la elaboración de este mapa, podemos destacar: autorización para la implementaciónde loteos publicada en documentos oficiales del municipio; entrevista con agentes inmobiliarios; consultas sobre las compañías y sus respectivos socios en sitios web como <https:// www.infoplex.com.br/> y <http://www.consultasocio.com>.

${ }^{9}$ La fecha de inicio de la "tierra cautiva” en Brasil se produjo con la Ley de Tierras, de 1850. Por medio de esta ley, el Estado aseveraba la relación entre la tierra y el capital. Para Martins (2010) se garantizaban los intereses de hacendados y de los comerciantes en la inminencia de transformaciones en las condiciones del régimen esclavista, determinando la adquisición de tierras por compra y venta, y legalizando la posesión de los títulos de sesmarias de cualquier dimensión no confirmados. La élite, que acumulaba riqueza con el monopolio del esclavo, pasó a acumular con el monopolio de la tierra. Según Martins (1994, p. 32), la noción de "renta capitalizada" traspuesta al esclavo pasó a la tierra: "la renta capitalizada del esclavo se convertía en renta territorial capitalizada: en un sistema de tierras libres, el trabajo tenía que ser cautivo; en un sistema de trabajo libre, la tierra tenía que ser cautiva” (énfasis agregado).

${ }^{10}$ Según Bonduki y Rolnik (1982), existencinco agentes responsables por la formación de los loteos periféricos: el propietario de tierras, el que lotea la propiedad, el corredor, los compradores residentes y el Estado.

${ }^{11}$ El modo por el cual se dio el proceso de formación, conservación y dominio de la propiedad privada de tierras en Brasil, por sujetos y clases sociales específicas, ilumina lo que Martins (1994), nombra "poder del retraso". Según el autor, la alianza entre la tierra y el capital, ampliamente discutida en sus obras, así como relaciones de corrupción e intercambio de favores, en una superposición total de lo público con lo privado, son elementos fundadores de la sociedad brasileña.

${ }^{12}$ Lo que hace los medios locales, el abrigo y la política, como detallado por Cerutti (2004).

13 El Programa Minha Casa Minha Vida (MCMV), implementado el 2009, fue anunciado como teniendo la finalidad de intentar reducir el déficit habitacional brasileño por medio de la construcción de conjuntos de viviendas. Sin embargo, el MCMV, como varios estudios indican -entre ellos, los de Santos (2015)-, está más próximo a un programa de financiamiento para impulsar la economía que a un programa de vivienda. Si el MCMV puede convertirse en un posible camino para el acceso a viviendas -y a la propiedad-para las familias que no lograrían hacerlo de otra manera, también es un mecanismo para la reproducción de los negocios inmobiliarios, principalmente en las periferias de las ciudades, conformando un elemento que conduce a la intensificación del proceso de segregación.

\section{Bibliografía}

Albaladejo, C. (2013). Dinámica de la inserción territorial de la agricultura pampeana y emergencia del agribusiness. En C. Gras y V. Hernández. (coord.) El agro como negocio: producción, sociedad y territorios en la globalización.pp. 67-96.Buenos Aires, Argentina: Biblios.

Almeida, L. S. (2013). Gaúchos, festas e negócios: o agronegócio da soja no Meio-Norte mato-grossense.(Tesis de maestría).Universidade Federal do Rio de Janeiro, Rio de Janeiro, Brasil. Recuperado de http:// campohoje.net.br/sites/default/files/acervo/Tese_luciana_almeida.pdf

Becker, B. K. (1982). Geopolítica da Amazônia: a nova fronteira de recursos. Rio de Janeiro, Brasil: Zahar.

Bonduki, N. y Rolnik, R. (1982). Periferia da Grande São Paulo: reprodução do espaço como expediente de reprodução da força de trabalho. En E. Maricato. (coord.). A produção capitalista da casa (e da cidade) do Brasil industrial. São Paulo, Brasil: Alfa-Ômega. 
Brenner, N. (2014). Urban theory without and outside. En: N. Brenner(ed). Implosions/Explosions: towards a study of planetary urbanization.Berlim, Germany: Jovis.

Burgarelli, R., Duarte, G., y Toledo; J. R. de. (2016, 13 de agosto). 1\% dos donos de imóveis concentra 45\% do valor imobiliário de São Paulo.O Estado de São Paulo.Recuperado de http://www.estadao.com.br/noticias/ geral,1-dos-donos-de-imoveis-concentra-45-do-valor-imobiliario-de-sao-paulo,10000069287

Câmara Municipal De Primavera Do Leste. História de Primavera do Leste.Recuperado de http://camarapva.com.br/ livro.pdf

Cerutti, L. G. (2004). Deslocamento social e trabalho temporário: práticas e relatos de trabalhadores em Primavera do Leste - MT. (Tesisdoctoral). Universidade Federal de Mato Grosso, Cuiabá, Brasil. Recuperado de http://ppghis.com/ppghis/biblioteca-virtual-2/dissertacoes/download/5-dissertacoes/133-deslocamento-sociale-trabalho-temporario-praticas-e-relatos-de-trabalhadores-em-primavera-do-lestemt.html

Elias,D. (2006). Globalização e fragmentação do espaço agrícola do Brasil. Scripta Nova.Revista electrónica de geografía y cienciassociales, (10). Recuperado de http://www.ub.edu/geocrit/sn/sn-218-03.htm.

Fazeres, A. (2007, 16 de mayo). Estouro no Xingu. Eco. Recuperado de http://www.oeco.org.br/reportagens/1944oeco_22068/

Gosch, J. (2017, 30 de enero). Denúncia ao MPE aponta que Binotti utilizou cargo para benefício próprio. $R$ Dnews. Recuperado de http://www.rdnews.com.br/executivo/denuncia-ao-mpe-aponta-que-binotti-utilizoucargo-para-beneficio-proprio/80435

Graziano Da Silva, J. (1999).O novo rural brasileiro.Campinas, Brasil: Unicamp/Instituto de Economia.

Lefebvre, H.(2004) A Revolução Urbana. Belo Horizonte, Brasil; Humanitas.

Lefebvre, H. (2006).O Direito à Cidade. São Paulo, Brasil: Centauro.

Martins, J. de S. (1994).O Poder do Atraso: Ensaios de Sociologia da História Lenta. São Paulo, Brasil: Hucitec.

Martins, J. de S. (1997). Fronteira: A degradação do outro nos confins do humano. São Paulo, Brasil: Hucitec.

Martins, J. de S. (2010). O Cativeiro da Terra.São Paulo, Brasil: Contexto.

Martins, S. M. M. (1993). A cidade "sem infância” no universo pioneiro de Chapadão do Sul (MS).(Tesisdoctoral). Universidade de São Paulo, São Paulo, Brasil.

Mistério Público denuncia prefeito de MT por compra de votos.(20 de marzo de 2007). Folhaon line. Recuperado de http://www1.folha.uol.com.br/folha/brasil/ult96u90461.shtml

Moreno, G. (2007). Terra e Poder em Mato Grosso: Políticas e Mecanismos de Burla 1892 - 1992. Cuiabá, Brasil: EdUFMT/Entrelinhas/FAPEMAT.

Oliveira, A. U. (1997). A fronteira amazônica mato-grossense: grilagem, corrupção e violência. Tesis (Livre Docência) - Universidade de São Paulo, São Paulo, Brasil. Recuperado de http://agraria.fflch.usp.br/sites/ agraria.fflch.usp.br/files/A\%20FRONTEIRA\%20AMAZ\%C3\%94NICA\%20MATO\%20GROSSENSE.pdf

Oliveira, A. U. (2007). Modo capitalista de produção, agricultura e Reforma Agrária. São Paulo, Brasil: Labur Edições. 
Ribeiro, E. (2017, 06 de julio). Governo entrega em Sorriso maior conjunto habitacional do país.Governo do Estado de Mato Grosso. Recuperado de http://www.mt.gov.br/-/7770205-governo-entrega-em-sorriso-maiorconjunto-habitacional-do-pais

Santos,C. R. S (2015). A fronteira urbana: urbanização, industrialização e mercado imobiliário no Brasil. São Paulo, Brasil: PPGH - USP/FAPESP/ Annablume.

Santos, M (2008). Técnica, Espaço, Tempo: Globalização e meio técnico-científico-informacional.São Paulo, Brasil: Edusp.

Siqueira, D (2007, 24 de mayo). Juiz nega habeas corpus para 3 suspeitos de crimes ambientais.Gazeta Digital. Recuperado de https:/www.gazetadigital.com.br/conteudo/show/secao/ 9/materia/143462/t/juiz-nega-habeascorpus-para-3-suspeitos-de-crimes-ambientais

Volochko, D. (2013). Da extensão do campo à centralização do urbano: elementos para o debato da produção do espaço em Mato Grosso. Revista Mato-Grossense de Geografia,(16), 18-38.Recuperado de http:// periodicoscientificos.ufmt.br/ojs/index.php/geografia/article/view/768/1040

Volochko, D. (2015). Terra, poder e capital em Nova Mutum - MT: elementos para o debate da produção do espaço nas ‘cidades do agronegócio’. GEOgraphia,(17), 40-67.Recuperado de http://www.geographia.uff.br/ index.php/geographia/article/view/875/587 